\title{
Article \\ Surgery after Failed Transcatheter Aortic Valve Implantation: Indications and Outcomes of a Concerning Condition
}

\author{
Mohamed Salem 1,*(1), Christina Grothusen ${ }^{1}$, Mostafa Salem ${ }^{2}$, Derk Frank ${ }^{2,3}$, Mohammed Saad ${ }^{2}$, Markus Ernst ${ }^{1}$,

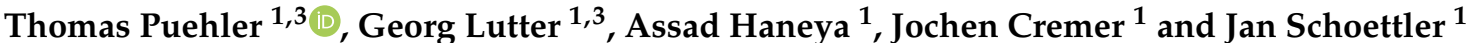 \\ 1 Department of Cardiovascular Surgery, Campus Kiel, University Hospital Schleswig-Holstein, 24105 Kiel, \\ Germany; christina.grothusen@uksh.de (C.G.); markus.ernst@uksh.de (M.E.); Thomas.Puehler@uksh.de (T.P.); \\ Georg.Lutter@uksh.de (G.L.); assad.haneya@uksh.de (A.H.); Jochen.Cremer@uksh.de (J.C.); \\ Jan.Schoettler@uksh.de (J.S.) \\ 2 Department of Cardiology and Angiology, Campus Kiel, University Hospital Schleswig-Holstein, 24105 Kiel, \\ Germany; mostafa.salem@uksh.de (M.S.); derk.frank@uksh.de (D.F.); Mohammed.Saad@uksh.de (M.S.) \\ 3 DZHK (German Centre for Cardiovascular Research), Partner Site Hamburg/Kiel/Lübeck, Potsdamer Str. 58, \\ 10785 Berlin, Germany \\ * Correspondence: Mohamed.salem@uksh.de; Tel.: +49-(0431)-5002-2002 (ext. 67089); Fax: +49-(0431)-5002-2004
}

\section{check for}

updates

Citation: Salem, M.; Grothusen, C.;

Salem, M.; Frank, D.; Saad, M.; Ernst, M.; Puehler, T.; Lutter, G.; Haneya, A. Cremer, J.; et al. Surgery after Failed Transcatheter Aortic Valve Implantation: Indications and Outcomes of a Concerning Condition. J. Clin. Med. 2022, 11, 63. https:// doi.org/10.3390/jcm11010063

Academic Editor:

Maurizio Taramasso

Received: 28 October 2021

Accepted: 20 December 2021

Published: 23 December 2021

Publisher's Note: MDPI stays neutral with regard to jurisdictional claims in published maps and institutional affiliations.

Copyright: (c) 2021 by the authors. Licensee MDPI, Basel, Switzerland. This article is an open access article distributed under the terms and conditions of the Creative Commons Attribution (CC BY) license (https:// creativecommons.org/licenses/by/ $4.0 /)$

\begin{abstract}
Objectives: The number of transcatheter aortic valve implantations (TAVI) has increased enormously in recent decades. Transcatheter valve prosthesis failure and the requirement of conventional surgical replacement are expected to attract more focus in the near future. Indeed, given the scarcity of research in this field, the next decade will likely represent the beginning of a period of meaningful exploration of the degenerative changes that occur with transcatheter valves. The current study represents-through a series of consecutive cases-one of the first analyses of the underlying causes of TAVI failure, i.e., degenerative, functional and infective, followed by surgical aortic valve replacement (SAVR) and postoperative outcome. Methods: Between October 2008 and March 2021, 2098 TAVI procedures, including 1423 with transfemoral, 309 with transapical, and 366 with transaortic access, were performed in our institution. Among these, $0.5 \%$ (number $(n)=11$ ) required acute SAVR $(n=6)$ within 7 days $(n=3)$ or later $(n=2)$, and were included in the study. Results: Valve stent dislocation was the most common cause of replacement (83\%). Causes of replacement within 7 days after TAVI were multifactorial. In the later course, endocarditis was the sole indication for SAVR after TAVI. TAVI with transapical or transaortal approach had a higher EuroSCORE II (10.9 (7.2-35.3) vs. 3.5 (1.8-7.8)). Their 30 -day mortality after surgical conversion was higher $(67 \%$ vs. $20 \%)$, when compared to those who underwent a transfemoral procedure. The longest documented survival beyond 30 days was 58 months. Conclusions: The causes of SAVR after TAVI failure are multifactorial, and include biological, physical and infectious factors. An acceptable midterm prognosis may be expected in patients with physical causes when dislocation of the catheter prosthesis is observed; in such cases, emergency conversion is required. Conversion due to infection, as in cases of endocarditis, had the worst outcome. Prognosis after conversion due to degeneration is still problematic, due to a lack of autopsies and the recent history of prosthetic implantations.
\end{abstract}

Keywords: TAVI degeneration; SAVR after TAVI; long-term outcome of TAVI

\section{Introduction}

Due to demographic changes, the incidence of aortic valve stenosis requiring treatment is increasing. While approximately 15,000 isolated aortic valve procedures were performed in Germany in 2010, nearly 25,000 were performed in 2019 [1]. For decades, the gold standard for the treatment of symptomatic aortic valve stenosis was conventional surgical aortic valve replacement (SAVR) alone [2]. Since 2006, transcatheter aortic valve implantation (TAVI) has been considered a well-established alternative technique [3]. In 2017 , for the first time, more than half of isolated aortic valve procedures in Germany were performed as TAVI, and in 2019, the TAVI proportion was already around $60 \%$ [1]. 
According to current recommendations, TAVI is the procedure of choice for older and sicker patients, i.e., those aged 75 years and older with a Society of Thoracic Surgeons Score (STS Score) or EuroSCORE II of at least 4\% [4]. TAVI application in younger patients with fewer comorbidities is still being investigated in clinical trials [5,6]. If possible, TAVI is performed via the transfemoral approach (TF-TAVI) [4]. In cases of small diameters of femoral arteries, peripheral arterial occlusive disease and severe atherosclerosis or marked kinking of the descending aorta, TAVI can also be applied via the left ventricular apex (TA-TAVI) or the ascending aorta (TAO-TAVI), as well as transsubclavian and transcarotid, each using a minimally invasive technique $[7,8]$.

The results after TAVI are promising. The increasing expertise of heart teams and ongoing improvements of catheter valve implants have made TAVI safer as a low-complication procedure. Even the number of paravalvular leaks, which were seen more frequently in the past, is decreasing [9]. The durability of the implants appears to be sufficient, despite initial concerns [10]. However, the degenerative, biomedical and infectious factors leading to TAVI dysfunction have not yet been thoroughly investigated. Until now, TAVI durability data are based on the absence of reintervention or post-TAVI-SAVR in populations of elderly patients with an already a low survival rate of $30 \%$ at $5 \mathrm{y}[11,12]$. This is due to the recent history of prosthetic implantation. Moreover, the criteria of choosing TAVI patients such as old age and high comorbidities, and thus, the associated higher mortality rate, do not facilitate accurate analyses of the causes of the degenerative changes and failure of transcatheter prostheses.

In this paper, we report our experience regarding the various factors leading to TAVI dysfunction and the need for subsequent surgical replacement.

\section{Materials and Methods}

\subsection{Patients}

Between October 2008 and March 2021, 2098 consecutive TAVI procedures, including 1423 with transfemoral, 309 with transapical, and 366 with transaortic access, were performed in the cardiovascular department of the University Hospital of Schleswig-Holstein, Campus Kiel. TAVI was performed either through balloon-expandable or self-expandable valves. Retrospectively, we reviewed all patients who underwent surgical replacement of aortic valve following TAVI. The study population was defined as any SAVR after TAVI due to any form of deterioration of the primary implanted transcatheter aortic valve (TAV). The causes included malposition or dislocation of the TAV, paravalvular regurgitation, degeneration of TAV, annulus and ventricular perforation or infective endocarditis. SAVR were done either as an emergency procedure after unsuccessful primary TAVI or due to a prosthesis failure after successful TAVI. The cases were diagnosed either through transthoracic echocardiography or transesophageal echocardiography intra- or postoperative or through postoperative computer tomography. Data were collected and extracted from the institution's database and from medical records. The study protocol was approved by the local ethics committee in Kiel (D 415/21), and patient consent was obtained prior to and during hospital stay.

\subsection{Statistical Analysis and Definitions}

Descriptive statistics are reported as mean \pm SD for normally distributed continuous variables or otherwise as median and 25th-75th percentile (interquartile range). Absolute and relative frequencies are reported for categorical variables. A univariate comparison between the groups for categorical variables was made using the $x^{2}$ and the Fisher's exact test. A survival analysis was performed with the Kaplan-Meier method through extraction from the city database. The normality of continuous variables was assessed by Kolmogorov-Smirnow-Test. A statistical analysis was performed using the SPSS Statistics software (Version 18.0) and Stata 10 SE (Stata Corp., College Station, TX, USA). The primary endpoint was 30-day mortality. Secondary endpoints were intraoperative variables and 
postoperative course (e.g., ventilation time, bleeding, acute renal failure, neurological complications and late mortality).

\subsection{Surgical Technology}

All operations were done either as emergency procedures (such in cases of dislocation of the TAV, annulus rupture or coronary ostium occlusion during the primary TAVI procedure), or either on an urgent or elective basis (such in cases of late deterioration of valve function due to high grade paravalvular leak or endocarditis). Surgery was performed via median sternotomy using cardiopulmonary bypass and cardioplegic cardiac arrest. Salvage of the dislocated valve stents into the distal ascending aorta or the aortic arch sometimes required circulatory arrest and deep hypothermia. A transverse supracoronary aortic incision was made to remove dislocated valve stents and to visualize the aortic root. In SAVR cases after initially successful TAVI, the deployed wire meshes of the transcatheter valve were separated from the aortic wall with a dissector, and the prosthetic stent was then removed piece by piece, using a wire cutter if necessary. Finally, after excision of the aortic valve leaflets and careful decalcification of the aortic valve annulus, implantation of a biological prosthetic heart valve was performed in the usual manner. In cases of annulus rupture, a biological patch was used to strengthen the aortic wall.

\section{Results}

\subsection{Demographic Data and Preoperative Variables}

Between October 2008 and March 2021, 2098 TAVI procedures, including 1423 with transfemoral, 309 with transapical, and 366 with transaortic access, were performed in our institution. Among these, $0.52 \%(n=11$; five patients $(45 \%)$ transfemoral TAVI (TF-TAVI), six patients (55\%) transaortal or apical TAVI (TA/TAO-TAVI)) of patients underwent SAVR after TAVI failure, of which six were done on an emergency basis, three within 7 days, and two at a later time. The clinical characteristics of this population are shown in Table 1 . The median age was 79 years (interquartile range (64-85) and four (36\%) were female. The mean EuroSCORE II was 7.8 (1.8-35.3). Ten patients (91\%) suffered from coronary heart disease with previous coronary stenting. Four patients $(36 \%)$ required dialysis and seven $(64 \%)$ presented with peripheral arterial disease (PAD). When comparing the preoperative demographic data between TF-TAVI und TA/TAO TAVI, we found that patients with surgical TAVI were more often male (83\% vs. $40 \%$ ), had a higher EuroSCORE II (median $10.9(7.2-35.3)$ vs. $3.5(1.8-7.8)$ ), and tended to have more chronic obstructive lung disease ( $83 \%$ vs. $20 \%$ ), renal insufficiency with dialysis (50\% vs. $20 \%$ ), and peripheral artery disease (83\% vs. $40 \%$ ), Table 1.

Table 1. Preoperative variables.

\begin{tabular}{|c|c|c|c|}
\hline & $\begin{array}{c}\text { Total } \\
(n=11)\end{array}$ & $\begin{array}{c}\text { TF-TAVI } \\
(n=5)\end{array}$ & $\begin{array}{l}\text { TA/TAO-TAVI } \\
(n=6)\end{array}$ \\
\hline Male gender $(n)$ & $7(64 \%)$ & $2(40 \%)$ & $5(83 \%)$ \\
\hline Age (years) & $79(64-85)$ & 78 (76-79) & $83(64-85)$ \\
\hline EuroSCORE II & $7.8(1.8-35.3)$ & $3.5(1.8-7.8)$ & $10.9(7.2-35.3)$ \\
\hline Previous cerebral insult $(n)$ & $2(18 \%)$ & $1(20 \%)$ & $1(17 \%)$ \\
\hline Coronary artery disease $(n)$ & $10(91 \%)$ & $5(100 \%)$ & $5(83 \%)$ \\
\hline Previous coronary stenting $(n)$ & $10(91 \%)$ & $5(100 \%)$ & $5(83 \%)$ \\
\hline Previous cardiac surgery $(n)$ & 0 & 0 & 0 \\
\hline Obstructive lung disease $(n)$ & $6(55 \%)$ & $1(20 \%)$ & $5(83 \%)$ \\
\hline Dialysis $(n)$ & $4(36 \%)$ & $1(20 \%)$ & $3(50 \%)$ \\
\hline Peripheral artery disease $(n)$ & $7(64 \%)$ & $2(40 \%)$ & $5(83 \%)$ \\
\hline Implant size (mm) & $26(23-34)$ & $26(23-34)$ & $27.5(23-34)$ \\
\hline
\end{tabular}

TF-TAVI: transfemoral transcatheter aortic valve implantation, TA/TAO-TAVI: transapical/transaortal transcatheter aortic valve implantation. 


\subsection{Pro-Procedual TAVI-Metrics}

TAVI valve sizing and design were based on annulus dimension (mainly diameter), as well as the distance between aortic valve annulus and both sinotubular junction and the right and left ostia. The important measurements are represented in Table 2. Calcium score was mainly assessed as ordinary CAC-Score, and in recent cases, was assessed through absolute Agatston-Score, Table 2.

Table 2. TAVI-Metrics.

\begin{tabular}{cccccc}
\hline Patient & $\begin{array}{c}\text { CAC-Score } \\
\text { (Agatston } \\
\text { Units) }\end{array}$ & $\begin{array}{c}\text { Aortic } \\
\text { Annulus } \\
\mathbf{( m m})\end{array}$ & $\begin{array}{c}\text { Sinotubular } \\
\text { Junction } \\
(\mathbf{m m})\end{array}$ & $\begin{array}{c}\text { Distance } \\
\text { between } \\
\text { RCA Ostia } \\
\text { to Annulus }\end{array}$ & $\begin{array}{c}\text { Distance } \\
\text { between LM } \\
\text { Ostia to } \\
\text { Annulus }\end{array}$ \\
\hline Patient 1 (m, 80Y) & Mild & $23 \times 29 \mathrm{~mm}$ & n.m & $20 \mathrm{~mm}$ & $17 \mathrm{~mm}$ \\
\hline Patient 2 (f, 78Y) & Severe & $20 \times 22 \mathrm{~mm}$ & n.m & $14 \mathrm{~mm}$ & $12 \mathrm{~mm}$ \\
\hline Patient 3 (f, 76Y) & $\begin{array}{c}\text { Extensive } \\
(2461)\end{array}$ & $20 \times 25 \mathrm{~mm}$ & $30 \mathrm{~mm}$ & $20 \mathrm{~mm}$ & $16 \mathrm{~mm}$ \\
\hline Patient 4 (m, 83Y) & High & $22 \times 28 \mathrm{~mm}$ & $29 \mathrm{~mm}$ & $7 \mathrm{~mm}$ & $16 \mathrm{~mm}$ \\
\hline Patient 5 (m, 65Y) & High & $23 \times 34 \mathrm{~mm}$ & $21 \mathrm{~mm}$ & $13 \mathrm{~mm}$ & $11 \mathrm{~mm}$ \\
\hline Patient 6 (f, 83Y) & Mild & $19 \times 23 \mathrm{~mm}$ & $22 \mathrm{~mm}$ & $6 \mathrm{~mm}$ & $13 \mathrm{~mm}$ \\
\hline Patient 7 (m, 85Y) & $\begin{array}{c}\text { Extensive } \\
(1955)\end{array}$ & $18 \times 24 \mathrm{~mm}$ & $29 \mathrm{~mm}$ & $21 \mathrm{~mm}$ & $16 \mathrm{~mm}$ \\
\hline Patient 8 (m, 78Y) & $\begin{array}{c}\text { Extensive } \\
(3028)\end{array}$ & $26 \times 33 \mathrm{~mm}$ & $29 \mathrm{~mm}$ & $15 \mathrm{~mm}$ & $8 \mathrm{~mm}$ \\
\hline Patient 9 (f, 76Y) & Mild & $17 \times 24 \mathrm{~mm}$ & $26 \mathrm{~mm}$ & $15 \mathrm{~mm}$ & $13 \mathrm{~mm}$ \\
\hline Patient 10 (m, 83Y) & $\begin{array}{c}\text { Extensive } \\
(2460)\end{array}$ & $25 \times 29 \mathrm{~mm}$ & $25 \mathrm{~mm}$ & $17 \mathrm{~mm}$ & $14 \mathrm{~mm}$ \\
\hline Patient 11 (m, 79Y) & $\begin{array}{c}\text { Extensive } \\
(1485)\end{array}$ & $22 \times 28 \mathrm{~mm}$ & $27 \mathrm{~mm}$ & $16 \mathrm{~mm}$ & $15 \mathrm{~mm}$ \\
\hline
\end{tabular}

CAC-Score: Coronary Artery Calcium score, n.m: no measurement, RCA: right coronary artery, LM: left main, f: Female, m: Male.

\subsection{Type of Prosthesis and Sizes of Implanted TAV}

The ratio between self-expanding to balloon-expanding prostheses was $55 \%$ vs. $45 \%$. The sizes ranged from 23 to $34 \mathrm{~mm}$ with no noticeable difference between the groups. Table 3 provides information on the prosthesis types and sizes used in previous TAVI procedures.

Table 3. TAVI prosthesis types and sizes.

\begin{tabular}{cccc}
\hline & $\begin{array}{c}\text { Total } \\
(\boldsymbol{n}=\mathbf{1 1})\end{array}$ & $\begin{array}{c}\text { TF-TAVI } \\
(\boldsymbol{n}=\mathbf{5})\end{array}$ & $\begin{array}{c}\text { TA/TAO-TAVI } \\
(\boldsymbol{n}=\mathbf{6})\end{array}$ \\
\hline${\text { Sapien } \mathrm{XT}^{\circledR}(n)}^{\circledR}$ & $2(18 \%)$ & $1(20 \%)$ & $1(17 \%)$ \\
\hline Sapien $3^{\circledR}(n)$ & $3(27 \%)$ & $1(20 \%)$ & $2(33 \%)$ \\
\hline CoreValve $^{\circledR}(n)$ & $5(45 \%)$ & $2(40 \%)$ & $3(50 \%)$ \\
\hline Symetis $^{\circledR}(n)$ & $1(9 \%)$ & $1(20 \%)$ & 0 \\
\hline
\end{tabular}

\subsection{Core Data and Indication of SAVR}

An analysis of the core data of the 11 patients showed that all subjects received a biological prosthetic heart valve, i.e., $64 \%$ received a porcine aortic valve and $36 \%$ a bovine pericardial tissue heart valve. One patient was stabilized with an extracorporeal circulatory support system (ECLS) even before SAVR. In another patient, closure of a newly 
formed ventricular septal defect (VSD) was required in addition to SAVR. The indication for surgical intervention SAVR was dislocation of TAV in five patients, either in LVOT or in the ascending aorta or aortic arch. One patient suffered from moderate to severe paravalvular leakage. Endocarditis as the cause of intravalvular regurgitation was documented in two patients. Two patients suffered from annulus perforation (one with VSD). Occlusion of the coronary left main trunk was a reason for SAVR in one patient. Late TAV degeneration was recognized at scheduled echocardiographic or computer tomography follow-up; see Table 4.

Table 4. Core Data and Indications for Intervention.

\begin{tabular}{|c|c|c|c|c|}
\hline Patient & TAVI & Problem & SAVR & $\begin{array}{c}\text { 30-Day } \\
\text { Mortality }\end{array}$ \\
\hline Patient 1 (m, 80Y) & $\begin{array}{c}\text { TA-TAVI } \\
26 \mathrm{~mm} \text { Sapien XT }\end{array}$ & $\begin{array}{c}\text { Dislocation into } \\
\text { left ventricular } \\
\text { outflow tract }\end{array}$ & $\begin{array}{c}\text { Single-stage } \\
27 \text { mm Hancock II }\end{array}$ & no \\
\hline Patient 2 (f, 78Y) & $\begin{array}{c}\text { TF-TAVI } \\
23 \mathrm{~mm} \text { Sapien XT }\end{array}$ & $\begin{array}{c}\text { Annulus } \\
\text { perforation }\end{array}$ & $\begin{array}{c}\leq 7 \text { days } \\
21 \mathrm{~mm} \\
\text { PERIMOUNT }\end{array}$ & no \\
\hline Patient 3 (f, 76Y) & $\begin{array}{c}\text { TF-TAVI } \\
26 \mathrm{~mm} \text { CoreValve }\end{array}$ & $\begin{array}{l}\text { Dislocation into } \\
\text { ascending aorta }\end{array}$ & $\begin{array}{c}\text { Single-stage } \\
23 \text { mm Hancock II } \\
\text { circulatory arrest }\end{array}$ & no \\
\hline Patient 4 (m, 83Y) & $\begin{array}{c}\text { TAO-TAVI } \\
29 \mathrm{~mm} \text { CoreValve }\end{array}$ & $\begin{array}{l}\text { Occlusion of the } \\
\text { coronary left } \\
\text { main trunk }\end{array}$ & $\begin{array}{l}\text { Single-stage } \\
21 \mathrm{~mm} \text { Trifecta }\end{array}$ & yes \\
\hline Patient 5 (m, 65Y) & $\begin{array}{c}\text { TAO-TAVI } \\
34 \mathrm{~mm} \text { CoreValve }\end{array}$ & $\begin{array}{c}\text { Paravalvular } \\
\text { leakage }\end{array}$ & $\begin{array}{c}\quad \leq 7 \text { days } \\
25 \mathrm{~mm} \text { Hancock II } \\
\text { ECLS before SAVR }\end{array}$ & yes \\
\hline Patient 6 (f, 83Y) & $\begin{array}{c}\text { TA-TAVI } \\
26 \text { mm Sapien } 3\end{array}$ & $\begin{array}{c}\text { Annulus } \\
\text { perforation with } \\
\text { VSD }\end{array}$ & $\begin{array}{c}\leq 7 \text { days } \\
21 \mathrm{~mm} \text { Trifecta } \\
\text { closure of VSD }\end{array}$ & yes \\
\hline Patient 7 (m, 85Y) & $\begin{array}{c}\text { TAO-TAVI } \\
29 \mathrm{~mm} \text { CoreValve }\end{array}$ & Endocarditis & $\begin{array}{c}>3 \text { months } \\
25 \text { mm Hancock II }\end{array}$ & no \\
\hline Patient 8 (m, 78Y) & $\begin{array}{c}\text { TF-TAVI } \\
34 \mathrm{~mm} \text { CoreValve }\end{array}$ & $\begin{array}{c}\text { Dislocation into } \\
\text { LVOT }\end{array}$ & $\begin{array}{c}\text { Single-stage } \\
29 \text { mm Hancock II } \\
\text { ECLS after SAVR }\end{array}$ & no \\
\hline Patient 9 (f, 76Y) & $\begin{array}{c}\text { TF-TAVI } \\
25 \mathrm{~mm} \text { Symetis }\end{array}$ & $\begin{array}{l}\text { Dislocation into } \\
\text { ascending aorta }\end{array}$ & $\begin{array}{c}\text { Single-stage } \\
25 \mathrm{~mm} \text { Hancock II } \\
\text { circulatory arrest }\end{array}$ & yes \\
\hline Patient $10(\mathrm{~m}, 83 \mathrm{Y})$ & $\begin{array}{c}\text { TA-TAVI } \\
23 \text { mm Sapien } 3\end{array}$ & Endocarditis & $\begin{array}{c}>3 \text { months } \\
21 \text { mm Hancock II }\end{array}$ & yes \\
\hline Patient 11 (m, 79Y) & $\begin{array}{c}\text { TF-TAVI } \\
26 \text { mm Sapien } 3\end{array}$ & $\begin{array}{c}\text { Dislocation into } \\
\text { aortic arch }\end{array}$ & $\begin{array}{c}\text { Single-stage } \\
23 \mathrm{~mm} \\
\text { PERIMOUNT } \\
\text { circulatory arrest }\end{array}$ & no \\
\hline
\end{tabular}

\subsection{Timing of Surgery}

In six cases (55\%), a single-stage conversion was required. Three patients $(27 \%)$ underwent SAVR at 7 days after the TAVI procedure, and two (18\%) at an interval of more than 3 months after TAVI. Single-stage surgery ( $80 \%$ vs. $33 \%$ ) and dislocation of the catheter valve ( $80 \%$ vs. $17 \%)$ were observed more frequently in the group which had undergone transfemoral procedure, Table 5. 
Table 5. Timing of Surgery.

\begin{tabular}{cccc}
\hline & $\begin{array}{c}\text { Total } \\
(n=\mathbf{1 1})\end{array}$ & $\begin{array}{c}\text { TF-TAVI } \\
(\boldsymbol{n}=\mathbf{5})\end{array}$ & $\begin{array}{c}\text { TA/TAO-TAVI } \\
(\boldsymbol{n}=\mathbf{6})\end{array}$ \\
\hline Single-stage operation $(n)$ & $6(55 \%)$ & $4(80 \%)$ & $2(33 \%)$ \\
\hline Two-stage $\leq 7$ days $(n)$ & $3(27 \%)$ & $1(20 \%)$ & $2(33 \%)$ \\
\hline Two-stage $>3$ months $(n)$ & $2(18 \%)$ & 0 & $2(33 \%)$ \\
\hline Catheter valve dislocation $(n)$ & $5(45 \%)$ & $4(80 \%)$ & $1(17 \%)$ \\
\hline Annulus perforation $(n)$ & $2(18 \%)$ & $1(20 \%)$ & $1(17 \%)$ \\
\hline Paravalvular leakage $(n)$ & $1(9 \%)$ & 0 & $1(17 \%)$ \\
\hline Ventricular septal defect $(n)$ & $1(9 \%)$ & 0 & $1(17 \%)$ \\
\hline Left main trunk occlusion $(n)$ & $1(9 \%)$ & 0 & $2(17 \%)$ \\
\hline Catheter valve endocarditis $(n)$ & $2(18 \%)$ & 0 & \\
\hline
\end{tabular}

\subsection{Intraoperative Variables}

Procedual durations in cases of transfemoral or surgical TAVI did not differ significantly. A preference for a specific biological valve prosthesis could not be determined. Implant sizes did not differ in our comparison; see Table 6.

Table 6. Intraoperative Variables.

\begin{tabular}{cccc}
\hline & $\begin{array}{c}\text { Total } \\
(\boldsymbol{n}=\mathbf{1 1})\end{array}$ & $\begin{array}{c}\text { TF-TAVI } \\
(\boldsymbol{n}=\mathbf{5})\end{array}$ & $\begin{array}{c}\text { TA/TAO-TAVI } \\
(\boldsymbol{n}=\mathbf{6})\end{array}$ \\
\hline Bypass time $(\mathrm{min})$ & $122(74-187)$ & $122(74-140)$ & $127.5(106-187)$ \\
\hline Cross-clamp-time $(\mathrm{min})$ & $83(49-143)$ & $84(49-102)$ & $80(72-143)$ \\
\hline Circulatory arrest $(n)$ & $3(27 \%)$ & $2(40 \%)$ & $1(17 \%)$ \\
\hline Hancock II $(n)(n)$ & $7(64 \%)$ & $3(60 \%)$ & $4(67 \%)$ \\
\hline PERIMOUNT $^{\circledR}(n)$ & $2(18 \%)$ & $2(40 \%)$ & 0 \\
\hline Trifecta $^{\circledR}(n)$ & $2(18 \%)$ & 0 & $23(21-27)$ \\
\hline Implant size $(\mathrm{mm})$ & $23(21-39)$ & $23(21-29)$ &
\end{tabular}

\subsection{Postoperative Variables}

Patients who underwent SAVR after a failed surgical TAVI had a longer duration of mechanical ventilation (median $121(48-283)$ vs. $28(15-125)$ ) and appeared to require more frequent postoperative dialysis $(67 \%$ vs. $20 \%)$, associated with a longer stay in the intensive care unit (median 9.5 (2-26) vs. $3(2-6)$ ). Their 30-day mortality was higher than that of the group which had undergone the primary transfemoral procedure (67\% vs. $20 \%)$, Table 7.

Table 7. Postoperative Variables.

\begin{tabular}{cccc}
\hline & $\begin{array}{c}\text { Total } \\
(\boldsymbol{n}=\mathbf{1 1})\end{array}$ & $\begin{array}{c}\text { TF-TAVI } \\
(\boldsymbol{n}=\mathbf{5})\end{array}$ & $\begin{array}{c}\text { TA/TAO-TAVI } \\
(\boldsymbol{n}=\mathbf{6})\end{array}$ \\
\hline Stay on ICU $(\mathrm{d})$ & $5(2-26)$ & $3(2-6)$ & $9.5(2-26)$ \\
\hline Hospital length of stay $(\mathrm{d})$ & $15(2-45)$ & $15(5-20)$ & $17.5(2-45)$ \\
\hline Ventilation duration $(\mathrm{h})$ & $100(15-283)$ & $28(15-125)$ & $121(48-283)$ \\
\hline Tracheostomy $(n)$ & $2(18 \%)$ & 0 & $2(33 \%)$ \\
\hline Rethoracotomy $(n)$ & $2(18 \%)$ & $1(20 \%)$ & $1(17 \%)$ \\
\hline Delirium $(n)$ & $3(27 \%)$ & 0 & $3(50 \%)$ \\
\hline
\end{tabular}


Table 7. Cont.

\begin{tabular}{cccc}
\hline & $\begin{array}{c}\text { Total } \\
(\boldsymbol{n}=\mathbf{1 1})\end{array}$ & $\begin{array}{c}\text { TF-TAVI } \\
(\boldsymbol{n}=\mathbf{5})\end{array}$ & $\begin{array}{c}\text { TA/TAO-TAVI } \\
(\boldsymbol{n}=\mathbf{6})\end{array}$ \\
\hline Cerebral Insult $(n)$ & $2(18 \%)$ & $1(20 \%)$ & $1(17 \%)$ \\
\hline Atrial fibrillation $(n)$ & $6(55 \%)$ & $3(60 \%)$ & $3(50 \%)$ \\
\hline Atrioventricular block $(n)$ & $4(36 \%)$ & $2(40 \%)$ & $2(33 \%)$ \\
\hline Pacemaker dependence $(n)$ & $1(9 \%)$ & $1(20 \%)$ & 0 \\
\hline Dialysis $(n)$ & $5(45 \%)$ & $1(20 \%)$ & $4(67 \%)$ \\
\hline Wound infection $(n)$ & $1(9 \%)$ & $1(20 \%)$ & $4(67 \%)$ \\
\hline 30-day mortality $(n)$ & $5(45 \%)$ & $1(20 \%)$ & 0 \\
\hline
\end{tabular}

Survival at the time of follow-up ranged from 1 to 58 months. Two patients are currently still alive. In total, a cumulative survival of nearly 10 patient-years has been achieved to date.

\section{Discussion}

At present, the use of TAVI is increasing in comparison to SAVR. TAVI is currently more applicable in medium- and in lower-risk patients, rather than only high-risk patients. This brings about a need for more adequate studies and strategies to be implemented, as not taking action regarding these young patients-as opposed to older, multimorbid patients-is no longer an option. The circumstances of TAVI failure, including etiology, incidence, management and outcome, are still under analysis. The causes of these failures should be more thoroughly analyzed in the near future. Thus, our study aimed to analyze the various early and late factors leading to TAVI failure.

Moreover, it is not clear whether patients after TAVI should undergo SAVR in emergency unsuccessful TAVI or in the course after primarily successful TAVI. In this context, there are only registry data for emergency cardiac surgical procedures during TFTAVI $[13,14]$. Both TAVI surgeries with transapical or transaortic access and two-stage surgeries later in the course were not considered in this registry. Furthermore, these registries did not focus in detail on the factors leading to TAVI failure.

The present study considers almost 13 years of TAVI experience. From 28 October 2008 to 31 January 2021, 2098 TAVI procedures were performed in Kiel, including 1423 TF-TAVI and 675 surgical TAVI, of which 309 were transapical and 366 were transaortic. During this time, a total of only 11 patients $(0.5 \%)$, i.e., six with primarily unsuccessful TAVI and five after primarily successful TAVI, underwent SAVR early-postoperatively for prosthesis-associated complications or because of subsequent prosthesis failure.

The causes of TAVI failure are multifactorial. According to the literature, during TF-TAVI, left ventricular perforation by the guidewire, annulus rupture, embolization or migration of the transcatheter valves, and aortic dissection are prominent as emergency indications for conversion to cardiac surgery [13]. These problems are generally associated with the TAVI, and consequently, are also observed in surgical implantations. In our work, a performed SAVR was considered an inclusion criterion, regardless of whether there the transfemoral or surgical approach was applied. Cases in which cardiac perforations were treated using a heart-lung machine, or even other cardiac surgical procedures without explantation of the TAVI prosthesis, such as isolated replacement of the ascending aorta for Stanford type A aortic dissection, were not included in our work. Therefore, the reason for primary failure of the TAVI procedure in our collective was mainly dislocations of the catheter valve. Only one of our patients required emergency conversion to SAVR for a different reason, namely, occlusion of the main left coronary trunk by the implanted valve stent.

Indication for cardiac surgery in the early-postoperative phase was due to to a periannular rupture, an annulus-near ventricular septal defect, and a catheter valve that was not 
fully deployed with increasing paravalvular leakage. All procedures in the early course after primary successful TAVI were required within 7 days of the procedure. The complications observed during this period were among the known intraprocedural complications. It is plausible that there are TAVI-associated problems that present with a latency of days in individual cases. According to the European Registry on Emergency Cardiac Surgery during TAVI, more than $90 \%$ of complications still occur during the TAVI procedure. Only about $3 \%$ of TAVI patients manifest problems requiring emergency cardiac surgery with a median sternotomy after more than $24 \mathrm{~h}$ [13].

Later, only two patients underwent SAVR because of manifest endocarditis of the valve stent. Endocarditis is not a TAVI-specific problem. In general, patients undergoing valve replacement are at higher than average risk of endocarditis. Prognoses of prosthetic endocarditis are compromised not only by local findings, but also by the inflammatory effects on the whole organism. Using a multicenter registry, Amat-Santos et al. demonstrated that the incidence of infective endocarditis 1 year after TAVI is $0.5 \%$. The majority of affected patients from this registry were treated conservatively, and overall hospital mortality was approximately $47 \%$, [14].

Overall, SAVR was associated with significant mortality in the patients included in our study, as expected. Even though none of the patients died on the operating table, i.e., the procedures were technically successful, the 30 -day mortality was $45 \%$. In 2013 , Hein et al. published an almost identical 30 -day mortality of $45.8 \%$ in patients who were converted from TAVI procedure to emergency cardiac surgery [15]. However, those authors studied only patients who required cardiac surgery immediately after TAVI; cardiac surgery at a later stage after TAVI was not considered in their publication. Furthermore, in contrast to our study, SAVR was not an explicit inclusion criterion in their registry analysis, and TAVI procedures with a primarily surgical approach were excluded from the outset.

Compared with data reported by Hein et al., our directly converted TAVI patients had a lower 30-day mortality of 33\%. Two-stage procedures within 7 days of TAVI had a 30 -day mortality of $67 \%$ in our collective, and we observed a 30 -day mortality of $50 \%$ in subsequent valve surgeries after primary successful TAVI due to prosthetic endocarditis.

In our comparison of transfemoral and surgical TAVI procedures, we found that patients in whom the transfemoral approach was chosen had a better prognosis after SAVR. Indeed, only one patient with TF-TAVI access died within 30 days after SAVR. The remaining decedents had surgical access, i.e., two of them via the left ventricular apex and two via the ascending aorta. Extrapolating from these facts, our patients had an $80 \%$ 30-day survival after SAVR for subjects with primary TF-TAVI and of approximately 33\% for those with primary surgical TAVI access. The lower survival of SAVR after surgical TAVI is certainly not due to the transapical or transaortic approach itself. Instead, it may be due to the fact that surgical TAVI patients have a different risk profile than those that are eligible for TF-TAVI [16]. In our collective, surgical TAVI patients had a higher EuroSCORE II, and findings requiring SAVR intraprocedurally or early in the course were more complex in such cases. Thus, only one patient required acute conversion after surgical TAVI because of a less complex prosthesis dislocation without concomitant cardiac problems. The failure of these interventions may be attributed to a wide range of factors.

According to our results, acute emergency surgery for primary unsuccessful TAVI is feasible with a reasonable risk, depending on the reason for conversion to SAVR. In cases of severe complications, such as circulatory collapse due physical occlusion of the left coronary main trunk that cannot be treated interventionally, the prognosis is very bad. In such cases, it may therefore be justified not to escalate treatment further. In contrast, in cases with only dislocated valve stent and existing circulatory stability, emergency SAVR may be carried out safely, because in this constellation, postoperative outcome seems to be acceptable, regardless of TAVI access. The 30-day mortality of these patients in our study was only $20 \%$, and in individual cases, we observed survival times of 1 to almost 5 years.

In our experience, two-stage SAVR for early postoperative cardiac complications after primary successful TAVI is unpromising with regard to the mid-term prognosis. 
In cases of late degenerative damage due to endocarditis of valve stents, we showed that SAVR is still associated with high risk. We also predict an acceptable chance for surgery on degenerated valvular stents, despite not having been assigned a patient with such characteristics for SAVR to date. Even if younger patients will more commonly undergo the TAVI procedure in the future, a significant number of such referrals is probably not to be expected, because, at most, mild and hemodynamically insignificant degeneration is observed on catheter valves 5 years after TAVI [16]. Moreover, subsequent problems not related to endocarditis, such as hemodynamically relevant degeneration or valvular and paravalvular insufficiencies, can, in principle, also be resolved by a repeat TAVI, [17].

\section{Conclusions}

Cases requiring emergency surgical intervention are most often those with improper TAV sizing and selection. Mostly, emergency cases may be attributed to valve dislocation either in the ascending aorta, aortic arch or LVOT. Such displacements either block the coronary ostia when moved in the direction of blood flow or lead to extensive aortic valve insufficiency when moved in the other direction. Those patients require an emergency thoracotomy and should be connected to a heart and lung machine. Also, TAV sizing mismatches play a significant role in cases requiring revision due to annulus rupture with or without VSD, sometimes even leading to the need for aortic dissection. Such cases must be also treated as life-threatening. In the study population, patients who presented in the late course with infective endocarditis also suffered from recurrent attacks of postoperative high-grade fever and shivering. Blood culture tests were mostly positive, and echocardiography proved the above diagnoses, and thus, the need for revision. The causes of SAVR after TAVI failure are multifactorial, including degenerative, physical or infectious factors. Acceptable mid-term prognoses were observed in patients with symptoms associated with the dislocation of the catheter prosthesis, for whom emergency conversions were required. Conversion due to infection, e.g., endocarditis, had the worst outcome. Prognoses after conversion due to degenerative causes are still lacking. This is due to a lack of enough autopsies and the recent history of prosthetic implantation. A proportion of affected patients can be saved by SAVR, both acute and subsequent. In cases of acute complications, rapid cardiac surgical intervention is required; in such instances, TAVI procedures must be performed at specialized centers with a broad cardiac surgical infrastructure. Cardiac surgery after TAVI should also be performed at TAVI centers with high levels of expertise, as these operations can be equally demanding.

\section{Limitations}

Only patients who had undergone a TAVI procedure in our hospital and received a SAVR during the procedure or at a later stage were included. Since such operations are a rarity, very few patients could be studied. Therefore, the conclusions drawn here should be considered with caution.

Author Contributions: Conceptualization, M.S. (Mohamed Salem) and J.S.; methodology, all authors.; software, M.S. (Mohamed Salem), J.S. and M.E.; validation, M.S. (Mohamed Salem), J.S.; formal analysis, M.S. (Mohamed Salem), J.S., M.E.; investigation, M.S. (Mohamed Salem) and J.S.; resources, M.S. (Mohamed Salem), J.S., A.H., D.F., M.S. (Mohammed Saad), and J.C.; data curation, M.S. (Mohamed Salem) and J.S.; writing-original draft preparation, M.S. (Mohamed Salem) and J.S.; writing — review and editing, M.S. (Mohamed Salem) and J.S.; visualization, all authors; writingreview and editing, all authors.; project administration, M.S. (Mohamed Salem) and J.S.; funding acquisition, none. All authors have read and agreed to the published version of the manuscript.

Funding: We acknowledge financial support by DFG within the funding programme Open Access Publizieren.

Institutional Review Board Statement: The study was conducted according to the guidelines of the Declaration of Helsinki, and approved by local Ethics Committee in Kiel (D 415/21). 
Informed Consent Statement: Informed consent was obtained from all subjects involved in the study.

Conflicts of Interest: The authors declare no conflict of interest.

\section{References}

1. Beckmann, A.; Meyer, R.; Lewandowski, J.; Markewitz, A.; Gummert, J. German heart surgery report 2019: The annual updated registry of the German society for thoracic and cardiovascular surgery. Thorac. Cardiovasc. Surg. 2020, 68, 263-276. [CrossRef] [PubMed]

2. Cribier, A.; Eltchaninoff, H.; Tron, C.; Bauer, F.; Agatiello, C.; Sebagh, L.; Bash, A.; Nusimovici, D.; Litzler, P.Y.; Bessou, J.P.; et al. Early experience with percutaneous transcatheter implantation of heart valve prothesis for the treatment of end-stage inoperable patients with calcific aortic stenosis. J. Am. Coll. Cardiol. 2001, 43, 698-703. [CrossRef] [PubMed]

3. Hörte, L.G.R.; Stahle, E. Observed and relative survival after aortic valve replacement. J. Am. Coll. Cardiol. 2000, $35,747-756$.

4. Baumgartner, H.; Falk, V.; Bax, J.J.; De Bonis, M.; Hamm, C.; Holm, P.J.; Iung, B.; Lancellotti, P.; Lansac, E.; Rodriguez Muñoz, D.; et al. 2017 ESC/EACTS Guidelines for the management of valvular heart disease. Eur. Heart J. 2017, 38, 2739-2791. [CrossRef]

5. Baron, S.J.; Arnold, S.V.; Wang, K.; Magnuson, E.A.; Chinnakondepali, K.; Makkar, R.; Herrmann, H.C.; Kodali, S.; Thourani, V.H.; Kapadia, S.; et al. Health status benefits of transcatheter vs surgical aortic valve replacement in patients with serve aortic stenosis at intermediate surgical risk: Results from the PARTNER 2 randomized clinical trial. JAMA Cardiol. 2017, 2, 837-845. [CrossRef] [PubMed]

6. Mack, M.J.; Leon, M.B.; Thourani, V.H.; Makkar, R.; Kodali, S.K.; Russo, M.; Kapadia, S.R.; Malaisrie, S.C.; Cohen, D.J.; Pibarot, P.; et al. Transcatheter Aortic-Valve Replacement with a Balloon-Expandaable Valve in Low-Risk Patients. N. Eng. J. Med. 2019, 380, 1695-1705. [CrossRef] [PubMed]

7. $\quad$ Reents, W.; Barth, S.; Griese, D.P.; Winkler, S.; Babin-Ebell, J.; Kerber, S.; Diegeler, A.; Zacher, M.; Hamm, K. Transfemoral versus transapical transcatheter aortic valve implantation: A single-centre experience. Eur. J. Cardio-Thorac. Surg. 2019, 55, 744-750. [CrossRef] [PubMed]

8. Dunne, B.; Tan, D.; Chu, D.; Yau, V.; Xiao, J.; Ho, K.M.; Yong, G.; Larbalestier, R. Transapical versus transaortic transcatheter aortic valve implantation: A systematic review. Ann. Thorac. Surg. 2015, 100, 354-361. [CrossRef] [PubMed]

9. Arai, T.; Lefèvre, T.; Hovasse, T.; Morice, M.-C.; Garot, P.; Benamer, H.; Unterseeh, T.; Hayashida, K.; Watanabe, Y.; Bouvier, E.; et al. Comparison of Edwards SAPIEN 3 versus SAPIEN XT in transfemoral transcatheter aortic valve implantation: Difference of valve selection in the real world. J. Cardiol. 2017, 69, 565-569. [CrossRef] [PubMed]

10. Mack, M.J.; Leon, M.B.; Smith, C.R.; Miller, D.C.; Moses, J.W.; Tuzcu, E.M.; Webb, J.G.; Douglas, P.S.; Anderson, W.N.; Blackstone, E.H.; et al. 5-Year outcomes of trancatheter aortic valve replacement or surgical aortic valve replacement for high surgical risk patients with aortic stenosis (PARTNER 1): A randomised controlled trial. Lancet 2015, 385, 2477-2484. [CrossRef]

11. Schmidt, T.; Frerker, C.; Alessandrini, H.; Schlüter, M.; Kreidel, F.; Schäfer, U.; Thielsen, T.; Kuck, K.-H.; Jose, J.; Holy, E.W.; et al. Redo TAVI: Initial experience at two German centres. EuroIntervention 2016, 12, 875-882. [CrossRef] [PubMed]

12. Haussig, S.; Pleissner, C.; Mangner, N.; Woitek, F.; Zimmer, M.; Kiefer, P.; Schlotter, F.; Stachel, G.; Leontyev, S.; Holzhey, D.; et al. Long-term follow-up after transcatheter aortic valve replacement. CJC Open 2021, 3, 845-853. [CrossRef] [PubMed]

13. Eggebrecht, H.; Vaquerizo, B.; Moris, C.; Bossone, E.; Lämmer, J.; Czerny, M.; Zierer, A.; Schröfel, H.; Kim, W.K.; Walther, T.; et al. Incidence and outcomes of emergent cardiac surgery during transfemoral transcatheter aortic valve implantation (TAVI): Insights from the European Registry on Emergent Cardiac Surgery during TAVI (EuRECS-TAVI). Eur. Heart J. 2018, 39, 676-684. [CrossRef] [PubMed]

14. Amat-Santos, I.J.; Messika-Zeitoun, D.; Eltchaninoff, H. Infective endocardotis after transcatheter aortic valve implantation. Circulation 2015, 131, 1566-1574. [CrossRef] [PubMed]

15. Hein, R.; Abdel-Wahab, M.; Sievert, H.; Kuck, K.-H.; Voehringer, M.; Hambrecht, R.; Sack, S.; Hauptmann, K.E.; Senges, J.; Zahn, R.; et al. Outcome of patients after emergency conversion from transcatheter aortic valve implantation to surgery. EuroIntervention 2013, 9, 446-451. [CrossRef] [PubMed]

16. Ferrari, E.; Eeckhout, E.; Keller, S.; Muller, O.; Tozzi, P.; Berdajs, D.; von Segesser, L.K. Transfemoral versus transapical approach for transcatheter aortic valve implantation: Hospital outcome and risk factor analysis. J. Cardiothorac. Surg. 2017, 12, 78. [CrossRef] [PubMed]

17. Sulženko, J.; Toušek, P.; Kočka, V.; Bednář, F.; Línková, H.; Petr, R.; Laboš, M.; Widimský, P. Degenerative changes and immune response after transcatheter aortic valve implantation. Comparison with surgical aortic valve replacement. J. Cardiol. 2017, 69, 483-488. [CrossRef] [PubMed] 